\title{
MICROSTRUCTURE AND SHAPE-MEMORY-PROPERTIES OF THERMO-MECHANICAL TREATED Fe-Ni-Co-Ti-ALLOYS
}

\author{
N. JOST \\ Institut für Werkstoffe, Ruhr-Universität Bochum, Postfach 1021 48, D-4630 Bochum 1, Germany
}

\begin{abstract}
It has been shown that ausaged $\mathrm{Fe}-\mathrm{Ni}-\mathrm{Co}-\mathrm{Ti}$ alloys exhibit shape-memory effects with a reversible martensitic transformation and a small temperature hysteresis between the forward and the reverse transformation. This is due to the precipitation of small coherent $(\mathrm{Ni}, \mathrm{Co}, \mathrm{Fe})_{3} \mathrm{Ti}$ particles which lead on the one hand to a very effective hardening of the austenite and on the other hand to high elastic back stresses after shearing together with the martensite into a metastable structure.

A combined thermomechanical treatment with homogeneously distributed dislocations can favour the homogeneous distribution of the particles. In this case, the obtainable shape memory effect can reach a maximum.

Mechanical and thermal properties were studied by means of hardness and dilatometric measurements. The microstructures before and after the martensitic transformation were investigated by optical microscopy. In order to proof the reversibility of the shape memory effect, springs of different dimensions were produced and their behaviour during the training and under different loads were investigated.
\end{abstract}

\section{Introduction.}

It is well known that the most important prerequisite for introducing shape-memory effects in $\mathrm{Fe}-\mathrm{Ni}-\mathrm{Co}-\mathrm{Ti}-$ alloys is an ausaging treatment at temperatures between $500^{\circ} \mathrm{C}$ and $700^{\circ} \mathrm{C} / 1,2 /$. The aim of this treatment is the formation of fine dispersed, ordered and coherent particles with the composition ( $\mathrm{Ni}, \mathrm{Co}, \mathrm{Fe}$ ) ${ }_{3} \mathrm{Ti}$. They lead to a effective hardening of the austenite. If the particles are small enough ( $d \leq d_{c}$, with $d_{c}$ as critical particle diameter), they may be "withsheared" in a metastable structure during the martensitic transformation. Thereby, elastic back stresses are created in the austenite. In such a condition a martensitic transformation leads only to a elastic deformation of the matrix, which, in turn, is favourable for a small temperature hysteresis, a lathlike martensite morphology, thermoelastic martensite and, thereby, for shape memory effects $|3,4|$.

An optimization can be obtained after a combined thermo-mechanical treatment. For example, this could be hot rolling at temperatures of about $1200^{\circ} \mathrm{C}$ with subsequent aging at $600{ }^{\circ} \mathrm{C}$. This process causes quite a complex microstructure consisting of austenite, shear bands and more or less homogeneously distributed precipitates $/ 5 /$.

The aim of this work is to show how the microstructure, the mechanical properties and the transformation behaviour, especially the transformation temperatures, can be influenced by a thermomechanical treatment. In addition (and for the first time for this kind of alloys !), the maximum obtainable shape memory effect will be proofed with springs of different diameters and a twoway-effect. 


\section{Experimental Methods.}

Fig. 1 shows the equilibrium diagram at room-temperature (RT) of the system $\mathrm{Fe}-\mathrm{Ni}-\mathrm{Co}$ and a schematic ternary alloy system in which the area of the investigated alloys is indicated (the Ticontent was $\mathrm{Ti}=4$ mass- $\%=$ const. for all alloys). It can be seen that, due to the thermodynamic principles of the martensitic transformation, in this alloy system the chemical composition of alloys which can martensitically transform is restricted.

All alloys were melted in a vacuum induction furnace under argon-atmosphere. Cast specimen pieces were hot rolled and vacuum homogenized at $\mathrm{T}=1250^{\circ} \mathrm{C}$ for $20 \mathrm{~h}$. After this treatment the alloys were austenitic, even at RT.

The bulk specimens were then again deformed by hot rolling between $\epsilon=0 \%$ and $70 \%$ reduction in thickness in steps of $\epsilon=10 \%$ at a temperature of $\mathrm{T}_{\epsilon}=1200^{\circ} \mathrm{C}$ and subsequent water quenched. After this they were aged at $\mathrm{T}_{\mathrm{a}}=600^{\circ} \mathrm{C}$ for various times and finally water quenched.

The specimens for the production of springs were first machined to a round profile. These pieces were then stringed to a wire with a diameter of $1 \mathrm{~mm}$ in several steps with short intermediate annealing treatments at $\mathrm{T}=1150^{\circ} \mathrm{C}$. After winding, the springs were also aged at $600^{\circ} \mathrm{C}$ for various times and water quenched.

The transformation temperatures were determined by dilatometric measurements in a temperature range between $400^{\circ} \mathrm{C}$ and $-196^{\circ} \mathrm{C}$. The hardness was measured as Vickers microhardness HV 0.025 . The microstructures were analyzed by optical microscopy (OM).

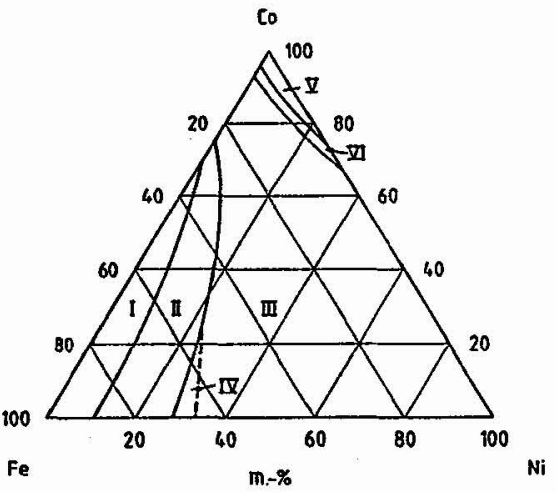

Fig. 1a: Ternary equilibrium diagram of the system $\mathrm{Fe}-\mathrm{Ni}-\mathrm{Co}$ at RT.

I: $\quad$ ferrite $(\alpha)$

II: martensite

III: $\quad$ austenite $(\gamma)$

IV: martensite after cooling to $-196^{\circ} \mathrm{C}$

V: hexagonal phase

VI: hexagonal phase and austenite

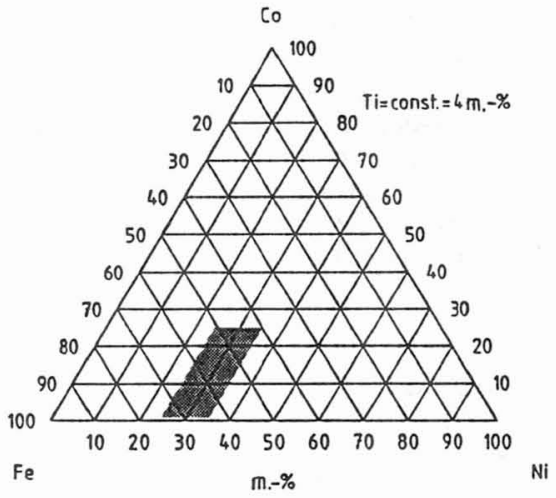

Fig. 1b: Ternary alloy system $\mathrm{Fe}-\mathrm{Ni}-\mathrm{Co}$, schematic. The investigated alloys are indicated.

3. Results and Discussion.

\subsection{Microstructures and Transformation Behaviour.}

The homogenization treatment leads to a austenitic microstructure in nearly all investigated alloys. The grain diameter amounts to about $\mathrm{d}=250 \mu \mathrm{m}$. Subsequent undercooling to $-196{ }^{\circ} \mathrm{C}$ results in a martensitic transformation, whereby the martensite is characterized by a lenticular morphology and a typical midrib (Fig. 2a). In this state the alloys exhibit no shape-memory-effect. 
Aging causes in a first stage precipitation of the coherent and ordered $\gamma^{\prime}$-phase with the chemical composition $(\mathrm{Ni}, \mathrm{Co}, \mathrm{Fe})_{3} \mathrm{Ti}$. Very long aging times or aging at comparatively high temperatures $\left(\mathrm{T}_{\mathrm{a}} \geq 700^{\circ} \mathrm{C}\right)$, respectively, lead to a high amount of discontinuous precipitation at grain boundaries. In this overaged condition the precipitated phase has the same chemical composition as $\gamma^{\prime}$ but it represents the incoherent and stable equilibrium phase $\eta$ with a hexagonal lattice structure. The precipitation processes are strongly influenced by the chemical composition of the alloys, especially by the $\mathrm{Ni}$-content. At low $\mathrm{Ni}$-concentrations the maximum in hardness and the overaged condition are reached after much shorter aging-times as in alloys with higher $\mathrm{Ni}$-contents.

As it could be shown in earlier investigations, the precipitation hardening has a strong influence on the martensite morphology and the transformation temperatures $/ 6 /$. Fig. 2b shows the typical lathlike martensite needles after aging to the maximum in hardness.

Low amounts of plastic deformation at high temperatures $\left(\mathrm{T}_{\epsilon}=120{ }^{\circ} \mathrm{C}\right)$ and before the ausaging lead to homogeneously distributed dislocations in the austenite. The resulting martensite morphology after aging and undercooling is nearly the same as shown in Fig. $2 \mathrm{~b}$. The only difference is that the martensite crystals are much more orientated in the rolling direction. Higher amounts of deformation produce large shear bands. Subsequent aging leads to a combined, continuous and, especially at deformed grain boundaries and shear bands, discontinuous precipitation (Fig. 3a). The latter ones can be analyzed as the stable $\eta$-phase, which implies the overaged condition. With longer aging times these precipitates grow very rapidly so that the amount of transformable residual austenite decreases. At the same time the austenite becomes more metastable due to the lower constituent of Nickel in the matrix. In this condition some investigated alloys (with low Ni-contents) are martensitic, even at RT (Fig. 3b). No residual austenite can be observed for the $70 \%$ deformed specimens and after about $10 \mathrm{~h}$ aging time. The specimens are completely transformed into a lamellar structure due to the discontinuous precipitation of $\eta$-phase.

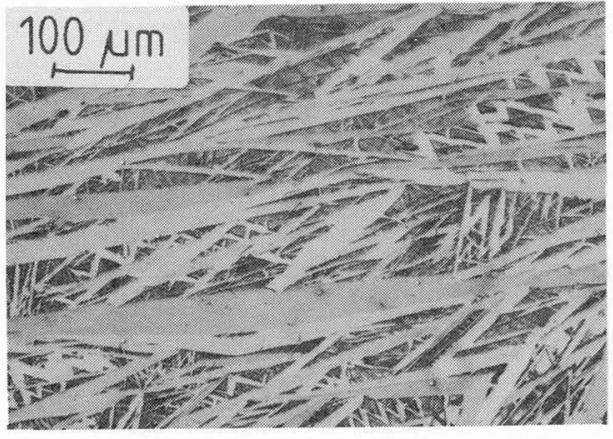

Fig. 2a: Typical martensite morphology after undercooling to $-196{ }^{\circ} \mathrm{C}$ of the unaged specimens.

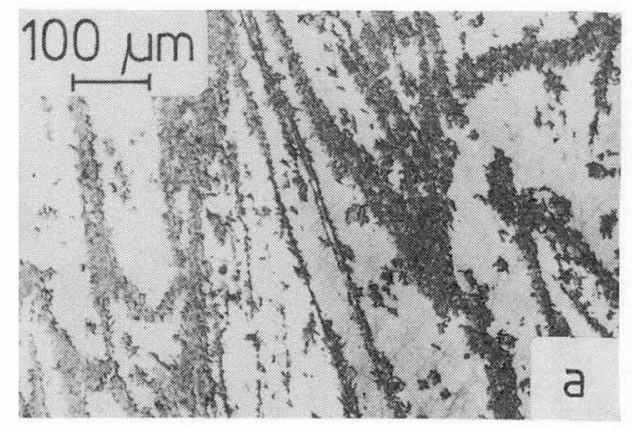

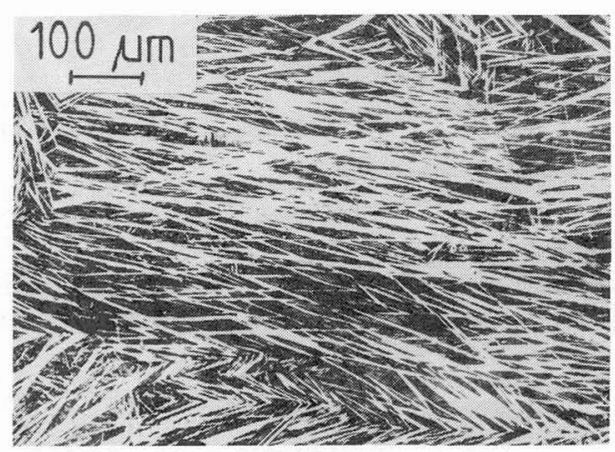

Fig. 2b: Morphology of thermoelastic martensite after aging and subsequent cooling to $-196^{\circ} \mathrm{C}$.

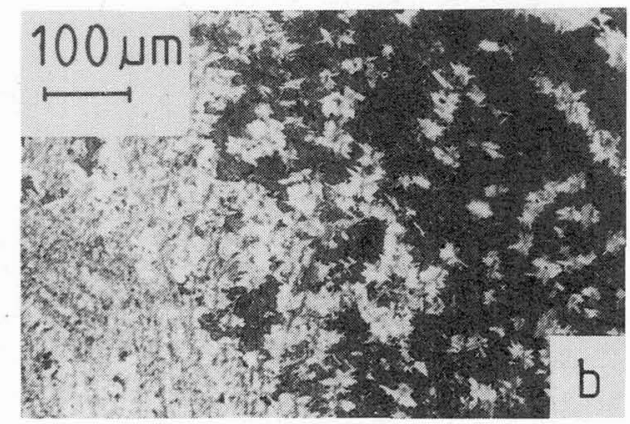

Fig. 3: Discontinuous precipitation of $\eta$-phase at deformed grain boundaries and shear bands.

a. $\mathrm{Fe}-29 \mathrm{Ni}-15 \mathrm{Co}-4 \mathrm{Ti}$, mass $-\%, \epsilon=50 \%, \mathrm{t}_{\mathrm{a}}=5 \mathrm{~h}$.

b. Fe-25 Ni-20 Co-4 Ti, mass-\%, $\epsilon=70 \%, \mathrm{t}_{\mathrm{a}}=5 \mathrm{~h}$. 
Fig. 4 summarizes as example the results of the $\mathrm{M}_{\mathrm{s}}$-temperatures and the hystereses of the alloy $\overline{\mathrm{Fe}}-29 \mathrm{Ni}-15 \mathrm{Co}-4 \mathrm{Ti}$ (mass. $-\%$ ) before and after ausaging at $600{ }^{\circ} \mathrm{C}$ and in dependence of different amounts of prior plastic deformation. Aging for only $10 \mathrm{~min}$. leads to a very strong decrease of the hystresis. This is due to the simultaneously observed strong decrease of the transformation temperatures $A_{s}$ and $A_{f}$. Thereby, the deformed specimens show a lower hysteresis as the undeformed. $M_{S}$ as well as $\Delta T_{\text {hyst }}$. become a minimum for $70 \%$ pre-deformed specimens and at aging times of about $30 \mathrm{~min}$. It is evident that the conditions with a small hysteresis exhibit thin plate martensite (Fig. 2b) and are favourable for shape-memory.

Due to the practical use of these new shape memory alloys the properties of springs were of special interest. In this connexion, wires with a diameter of $1 \mathrm{~mm}$ were stringed on a conventional wire drawing machine and subsequently wound to springs. In comparison to $\mathrm{NiTi}$-wires which show a maximum strain rate of $40 \%$ before the intermediate recrystallization, this value amounts to about $90 \%$ in the investigated $\mathrm{Fe}-\mathrm{Ni}-\mathrm{Co}-\mathrm{Ti}$-alloys. Fig. 5 a, b show the typical microstructures of such a wire before and after recrystallization. It can be clearly seen that the deformed state is characterized by a distinct formation of shear- and deformation-bands. After the finally recrystallization the grain size amounts to $30 \mu \mathrm{m}$. In this condition the wires can be coiled to springs.
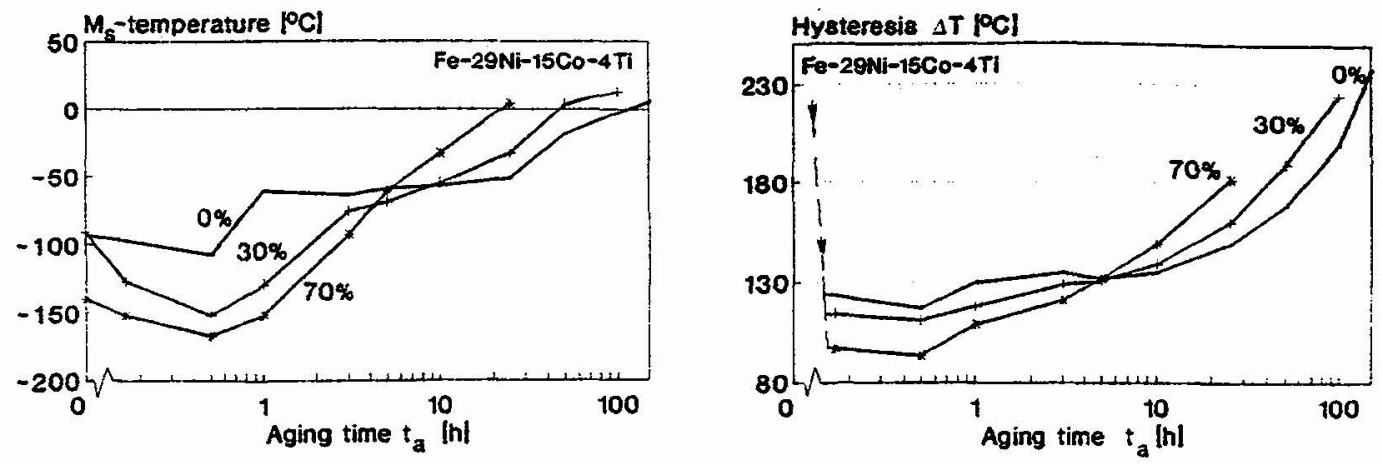

Fig. 4: Measurements of the martensite start temperatures $M_{\mathbf{S}}$ and the temperature hystereses

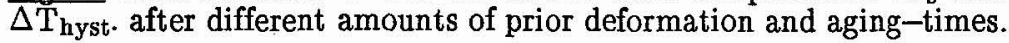

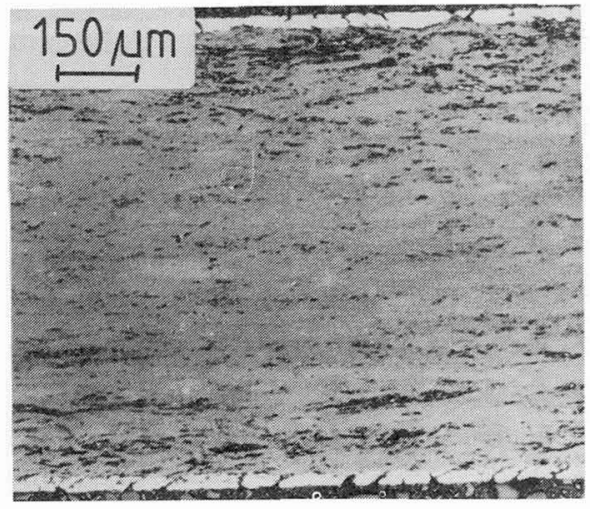

a

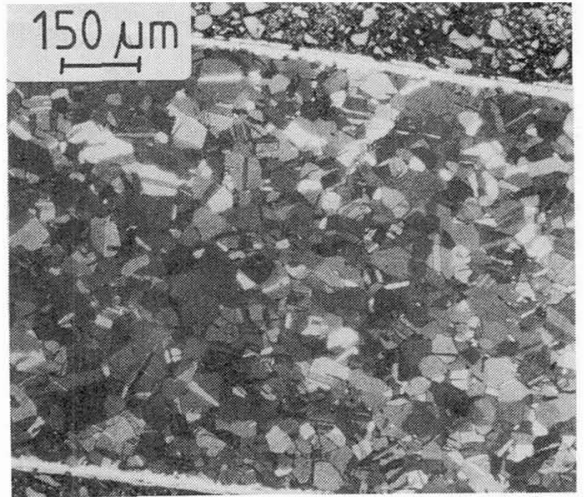

b

Fig. 5: Typical microstructures of wires (longitudinal sections) of the deformed (a) and the recrystallized conditions (b). 


\subsection{Shape Memory Effects.}

As it was discussed in earlier papers, ausaged $\mathrm{Fe}-\mathrm{Ni}-\mathrm{Co}-\mathrm{Ti}-$ alloys exhibit an one-way-effect as well as an two-way-effect $/ 5,6$. It could be shown that the amount of reversibility is strongly influenced by parameters like the starting microstructure, the transformation temperatures, especially the $M_{s}$ - and $A_{s}$-temperature and the temperature hysteresis.

Fig. 6.7 show some new results which were obtained from springs of the alloy $\mathrm{Fe}-27 \mathrm{Ni}-20 \mathrm{Co}-4$ Ti (mass-\%). The two-way-effect is defined as

$$
\mathrm{TWE}=\frac{\mathrm{l}_{\mathrm{spr}}(\mathrm{lt})-1_{\mathrm{spr}}(\mathrm{ht})}{\mathrm{l}_{\mathrm{spr}}(\mathrm{ht})} \cdot 100[\%]
$$

with " $\mathrm{spr}_{\mathrm{sp}}$ " for the length of the spring, "lt" for the low temperature condition and "ht" for the high temperature condition. It can be seen that after three training cycles the TWE reaches already $80 \%$, (Fig. 6a). The maximum obtainable reversibility amounts to about $90 \%$ after fifteen training cycles. An example for the shape change of such a spring is shown in Fig. $6 \mathrm{~b}$.

Under the application-oriented point of view it seems very interesting how the TWE is influenced by a load. Fig. 7a shows that there is only a little decrease of the TWE with increasing load. Even with a weight of $1000 \mathrm{~g}$ the TWE amounts to about $60 \%$ which is an excellent value for Fe-based alloys. Fig. 7b gives an example for the measuring technique and shows such a spring in its lowand high-temperature condition under an applied weight of $500 \mathrm{~g}$.

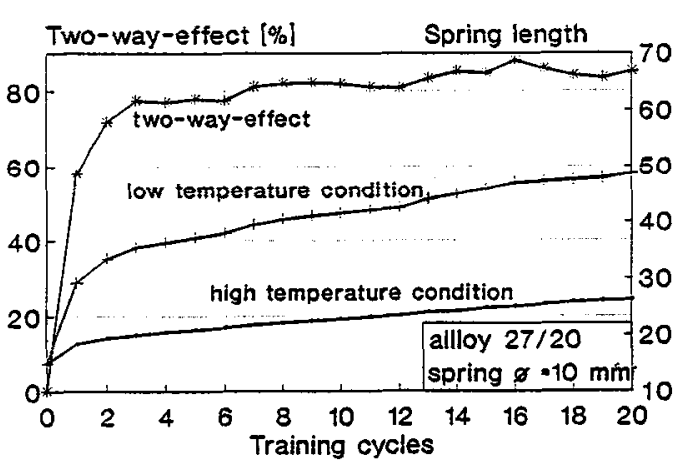

Fig. 6a: Two-way-effect and corresponding spring-lengths of the high- and low-temperature conditions in dependence of the number of training cycles.

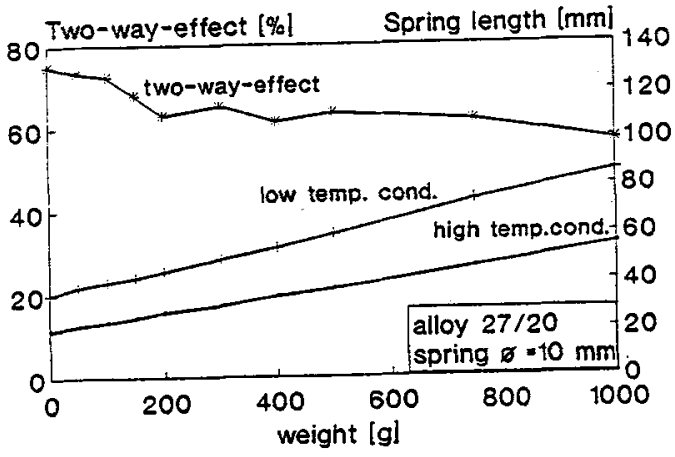

Fig. 7a: Two-way effect and corresponding spring-lengths of the high- and low-temperature conditions in dependence of an applied load.

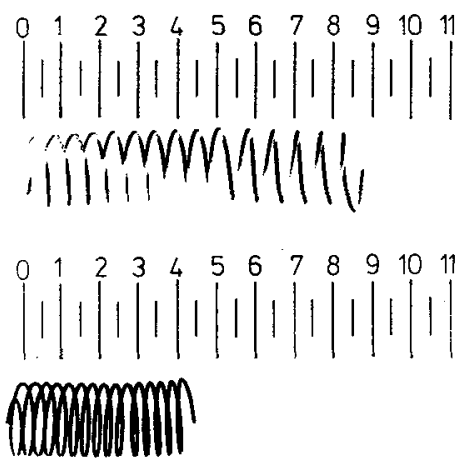

Fig. 6b: Example for a spring after 15 training-cycles, above: low temperature shape, below: high temperature shape.

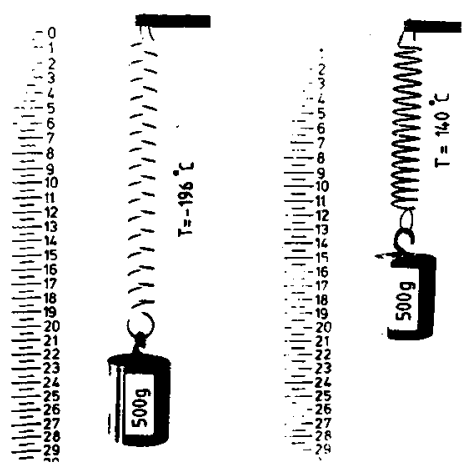

Fig. 7b: Example for a spring in the highand low temperature condition and with a weight of $500 \mathrm{~g}$. 
In order to draw a further comparison between the properties of springs of the investigated $\mathrm{Fe}-\mathrm{Ni}-\mathrm{Co}-\mathrm{Ti}-$ alloys and a conventional binary $\mathrm{Ni}-50 \% \mathrm{Ti}$ alloy it should be useful to calculate their maximum available power or their specific work capacity, respectively:

$$
\mathrm{w}_{\text {spec. }}=\frac{\mathrm{F} \cdot \Delta \mathrm{l}}{\mathrm{v}_{\mathrm{spr}}}\left[\mathrm{kJ} / \mathrm{m}^{3}\right]
$$

with $\mathrm{F}=$ force, load (in $\mathrm{N}$ ), $\Delta \mathrm{l}=$ lifting of the spring, length change (in $\mathrm{m}$ ) and $\mathrm{v}_{\mathrm{spr}}=$ volume of the spring (in $\mathrm{m}^{3}$ ).

The results for different spring diameters are shown in Fig. 8a. It can be seen that the values of the Fe-based alloys are only half or third as high as the values of the NiTi-alloy. But these relation changes completely if the specific work is referred to the total costs (i.e. for the production and the further treatment to a spring), (Fig. 8b). In this connexion it can finally be assumed that the $\mathrm{Fe}-\mathrm{Ni}-\mathrm{Co}-\mathrm{Ti}$-alloys have an increasing chance to substitute conventional NiTi-alloys in some fields of application.

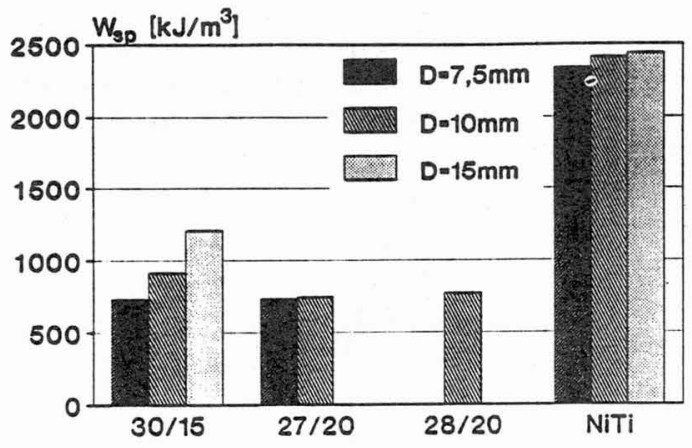

a

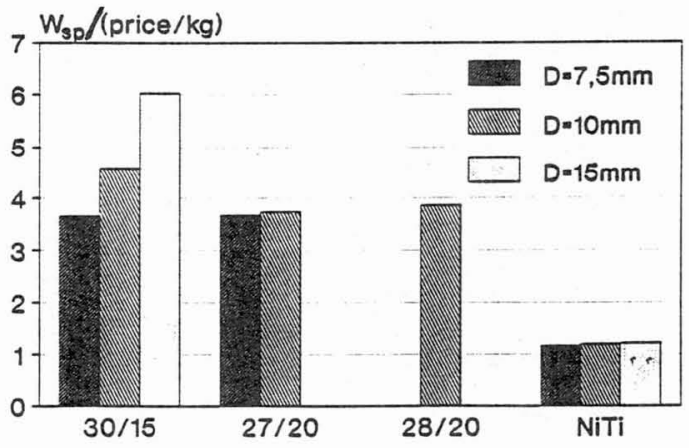

b

Fig. 8: Comparison of the maximum available specific power of three different $\mathrm{Fe}-\mathrm{Ni}-\mathrm{Co}-\mathrm{Ti}-$ springs (numerical data: $\mathrm{x} / \mathrm{y}=\mathrm{Ni} / \mathrm{Co}$ contents, $\mathrm{D}=$ spring diameter) and springs made of a binary $\mathrm{Ni}-50 \% \mathrm{Ti}$ alloy (a), (b) the same as (a) but in dependence of the costs per $\mathrm{kg}$.

\section{References:}

1) KOVAL, Y.U., KOKORIN, V.V. and KHANDROS, L.G., Fiz. met. metalloved. $\underline{48}$ (1979) $1309-1311$.

2) MAKI, T., et.al., Scripta Met. 18 (1984) 1105-1109.

3) JOST, N., Metall 44 (1990) 17-22.

4 JOST, N., Proc. Europ. Conf. on Martensitic Transformation in Science and Technology, E. Hornbogen, N. Jost (eds.) Bochum, FRG 1989, DGM Informationsgesellschaft, Oberursel, FRG (1990) 273-280.

5) JOST, N., Proc. Int. Conf. on Martensitic Transformations (ICOMAT 89) Sydney, Australia, B.C. Muddle (ed.), Materials Science Forum Vol. 56-58 (1990) 667-672.

6) ESCHER, K. and JOST, N., Proc. Europ. Conf. on Martensitic Transformation in Science and Technology, E. Hornbogen, N. Jost (eds.) Bochum, FRG 1989, DGM Informationsgesellschaft, Oberursel, FRG (1990) 281-286.

Acknowledgement:

Financial support of the German Science Foundation is gratefully acknowledged (DFG HO $325 / 20$ ). 